\title{
Food additive testing
}

By J. McL. Philp, Research Division, Unilever Limited, Unilever House, Blackfriars, London $\mathrm{EC}_{4}$

Starting with the testing carried out by the US Food and Drug Administration, the first regulatory agency in the world for food additives (Lehman, Laug, Woodward, Draize, Fitzhugh \& Nelson, 1949), test programmes which are obligatory have now been evolved (Food Protection Committee and Others; I967; Barnes, I960) and more tests are still being suggested (Epstein \& Shafner, r968; Epstein \& Röhrborn, I97I). I shall not describe in detail the various test procedures, some of which have certainly changed since the excellent review by Barnes \& Denz (1954) but I shall use personal experience with certain additives to cover programmes of testing, the value of studies in the human and some aspects of cancer tests.

Additives of all classes are used essentially for the benefit they confer on a foodstuff-to maintain the nutritive value, to improve the appearance or organoleptic qualities of the product and to present it to the consumer in a better form, either at point of sale or at the time of cooking or eating. A wider distribution of certain classes of food, availability out of season or greater convenience in cooking-all can accrue from the use of additives. 'The emulsifier, glyceran polyricinoleic acid ester (Polyster WOL), may be used for the production of water-in-oil emulsions, and it is of value in chocolate couverture or in block chocolate, and a very considerable programme which has been used for its evaluation is outlined in Table I. A programme of this scope is, of course, only possible with the combined efforts of graduates in several disciplines.

Throughout the programme relatively high doses were used and this is one example of a pharmacologically non-toxic additive with animals tolerating from 20 to $40 \mathrm{~g} / \mathrm{kg}$ body-weight in acute tests. As the additive was similar in many respects to fats and might be utilized by the body in much the same way as a natural fat, the first feeding tests used a combination of $9 \%$ Polyster WOL with $\mathbf{I} \%$ groundnut oil, giving a physiological level of fatty material to the rat without depriving the animal of essential fatty acids. This was in line with the usual $10 \%$ groundnut oil used in the standard synthetic diet. Even at this high level, the Polyster WOL had no effect on growth and was superior to starch as a source of energy, and nearly equivalent to groundnut oil. Only in one respect did it differ from groundnut oil and that was in giving minimal liver enlargement. Subsequent tests gave a satisfactory no-effect level. The liver enlargement was not in any way pathological, no lesions due to the additive ever appeared in the liver, and nuclear counts and deoxyribonucleic acid estimations indicated that the change was one of cell hypertrophy. The liver reverted to normal after the additive was removed from the diet 
Table I. Programme for biological evaluation of Polyster WOL (glyceran polyricinoleic acid ester)

Acute toxicity

Rats, mice, rabbits, chickens, guinea-pigs

Subacute toxicity

Rats-30-week and 45-week feeding trials, $9 \%$ Polyster WOL

Liver function studies, haematology, pathology

* Lack of effect on serum cholesterol

-Lack of effect on red cell fragility

90-d rat tests-0, 1, 2, 4 and $8 \%$ Polyster WOL

Organ functions, organ weights, pathology

9o-d chicken (non-rodent test) tests-2, 5, 10 and $15 \%$ Polyster WOL

Biochemistry, haematology, organ weights, pathology

Metabolism of Polyster WOL

Indirect:

*Absorption and metabolism by calorie-restricted rats

* Carcass composition after feeding $9 \%$ Polyster WOL

*Lack of effect on digestibility of groundnut oil or protein

"Lack of effect on lipase digestion of groundnut oil

"Lack of chylomicronaemia after feeding Polyster WOL

Direct:

Distribution of $\left[{ }^{14} \mathrm{C}\right]$ polyglycerol by whole-body autoradiography

Studies with ${ }^{14} \mathrm{C}$-marker fatty acids $\left(\left[\mathrm{I}-{ }^{14} \mathrm{C}\right]\right.$ oleic acid and $\left[\mathrm{I}-{ }^{14} \mathrm{C}\right]$ stearic acid) condensed with ricinoleic acid and incorporated into Polyster WOL

Studies with tritiated Polyster WOL prepared from tritiated polyricinoleic acid

Chronic toxicity

Growth in three generations

Breeding performance in three generations

Pathology

Carcinogenicity

2-year rat feeding, $5 \%$ Polyster WOL

80-week mouse feeding, $5 \%$ Polyster WOL

t2-year cutaneous application test with tats; 80 weeks with mice

t2-year co-carcinogenicity test with rats; 80 weeks with mice

2-year subcutaneous injection test with rats; 80 weeks with mice

Human studies

Digestion and absorption

Tolerance of high dose

*Special non-standard tests.

$\uparrow$ Tests of debatable value.

and it was considered that hypertrophy resulted from an adaptation to increased functional requirement. This could be considered analogous to enlargement seen during pregnancy (Wilson, Doell, Groger, Hope \& Gellatly, 1970). Although it was not considered that this indicated harm to the animal, the no-effect dietary level was calculated from the amount giving no liver change in the most susceptible animal $(2 \%)$.

\section{Non-standard test}

A non-standard test was developed to demonstrate whether or not Polyster WOL was utilized as a source of calories by the rat. Previously it had been shown that the weights of 4 -week-old rats remained fairly constant for 2 weeks when the 
diet was limited to $18 \mathrm{kcal} / \mathrm{d}$. The caloric intake of rats given $9 \%$ Polyster WOL in the diet for 9 weeks was restricted for $\mathrm{I} 7 \mathrm{~d}$ to a daily ration of $5 \mathrm{~g}$ fat-free diet providing $18 \mathrm{kcal} / \mathrm{d}$. When some of the animals were killed, the fat depots were found to be depleted, and carcass analysis for fat and free fatty acids confirmed that fat had been metabolized during the period of depletion. Subsequent feeding of the Polyster WOL to the remaining animals gave complete recovery of weight in $\mathbf{r} 4 \mathrm{~d}$. Thus there was evidence that the ester was utilized as a nutrient. However, when this work was reviewed by the UK authorities it was considered necessary to have more direct metabolic studies.

The subsequent metabolic studies utilizing radioisotopes showed that Polyster WOL is digested in the gut to give free polyglycerols, polyricinoleic acid and free ricinoleic acid. Lower polyglycerols (containing up to three glycerol units) are absorbed and excreted unchanged in the urine but higher polyglycerols are excreted in the faeces. Up to $90 \%$ of the fatty acid material is absorbed and metabolized. In this study one was really asking why the material was harmless.

\section{Human studies}

Much has been said and written (Food Protection Committees and Others, 1967 ; Freund, I965) about the use of human subjects in the safety evaluation of food additives. However, it may not always be realized that when one speaks of human studies one is not talking of studies similar to the screening work carried out in animals. When toxic effects are being sought, there is no substitute for well-planned animal studies. Human toxicity studies of adequate scope are not only impossible but are ethically undesirable. Moreover, it has been pointed out that many of the effects in man that are difficult to predict by animal studies are no easier to predict from studies in the normal human subject (Frazer, I964). Hayes (I 968) discusses human tests when biologically active chemicals such as pesticides are to be used and he provides a valuable review of international law on the subject. However, it is food additives which are under discussion here and, as mentioned before, they are not chosen for their biological activity and, in the main, have little or no toxicity.

The emulsifier Polyster WOL was examined for digestibility and absorption in man at the Metabolic Unit of Glasgow Royal Infirmary, which was at that time under the supervision of the late Dr J. C. Eaton. Volunteers were maintained two at a time for 3 weeks in the Metabolic Unit. It is essential to have results on the normal human, as opposed to that obtained from hospital patients, therefore normal volunteers were maintained under the dietary conditions of the test both with and without placebo. Normal values from such individuals and from previous trials provided the necessary background for comparison with results on treated individuals. The feeding regimen was designed on the basis of a fat-balance experiment, with an initial period for estimation of endogenous fat excretion $(6 \mathrm{~g} / \mathrm{d})$ followed by a period on the test material. The total period of observation was 3 weeks for each of the nineteen volunteers. The biochemical tests were done in Dr Eaton's laboratory and involved examination of serum proteins, liver functions, including thymol turbidity, serum bilirubin, serum cholesterol, serum glutamic 
pyruvic transaminase and serum cholinesterase, and one test for renal functionthe creatinine clearance test. The fat-balance tests showed that digestion and absorption took place, and there was no consistent effect of Polyster WOL on the various biochemical indices. This might be regarded as a fairly straightforward test but it is important to appreciate the need for normal values obtained in normal individuals, good control of the dietary regimen and discipline of the volunteers, the need for appropriate methods of handling fat in faeces and the value of expertise in production of food incorporating the test substance in such a way as to allow exaggerated amounts to be ingested.

Another test, also carried out at the Metabolic Unit but this time with the cooperation of Professor H. G. Morgan and Dr A. Fleck, was the examination of cyclamate for absorption and metabolism in man. This chemical had been widely used and had been the subject of much evaluation work supporting its safety in use. However, largely because of improved technology, early work showing no absorption or metabolism in man and animals came to be questioned. Kosima \& Ichibagase (1966) showed that in some rabbits, dogs and in one man, cyclamate was partially metabolized to cyclohexylamine (CHA). Leahy, Wakefield \& Taylor (1967) showed that out of forty individuals who were tested two excreted CHA in urine. This new metabolite had never previously been considered as a food additive, therefore the probability of its being produced during metabolism of such a widely distributed chemical was of some concern. However, there was some considerable confusion at first with regard to the interpretation of this work. There was even the suggestion that normal individuals excreted CHA in their urine in the absence of cyclamate in their diet. There was also some doubt as to the precise nature of the chemicals that might be present in any commercial sample of cyclamate, one suggestion being that if CHA were present initially, this would have some effect on the metabolism of cyclamate in the body. There was also the suggestion that dicyclohexylamine, a suspect carcinogen, might also be present. Appropriate analytical tests had therefore to be developed to ensure that not only was the specification of cyclamate adhered to, but that unequivocal evidence could be presented showing presence or absence of metabolites of cyclamate in urine and faeces of animals and man.

CHA was identified by comparison with a standard using gas-liquid chromatrography and mass spectrometry, and the analytical method was first applied to screen the urine of roo volunteers from the laboratory. This showed unequivocally that CHA was never present in the absence of cyclamate (Collings \& Favell, 1971). With various dosing regimens it was shown that of $\mathrm{I}_{4} \mathrm{I}$ individuals examined, $3^{6}$ excreted CHA after being dosed with cyclamate. There was considerable variation in what came to be known as the conversion rate, and it ranged from less than $\mathrm{r} \%$ to over $50 \%$ of the dose administered. Of some interest was the fact that with increasing doses of cyclamate, the CHA produced did not increase in proportion, although there was an increase in the absolute amount excreted. Further studies, utilizing the antibiotic ampicillin to control the gut flora, showed that the metabolism of cyclamate to CHA in man is probably due to a micro-organism in the gastro- 
intestinal tract. Similar studies in the pig and rat confirmed this site of conversion (Collings \& Favell, 1971).

This investigation involved determination of packed cell volume, haemoglobin, white blood cell count, blood film, creatinine, aspartate transaminase ( $E C$ 2.6.I.I.) (glutamic-oxaloacetic transaminase), alanine transaminase ( $E C$ 2.6.1.2) (glutamicpuruvic transaminase), alkaline phosphatase ( $E C$ 3.I.3.I), total and direct bilirubin, thymol turbidity, total protein and albumin; fourteen serum proteins were examined by electrophoresis. No significant changes were observed.

\section{Cancer}

One of the purposes of any food additive investigation is to discover if the material under test has carcinogenic potential such as would present a hazard if the chemical were eaten in the diet. It is usually assumed that the consumption of the additive might be continuous during most of man's lifetime. However, there is no suggestion that the individual will ever be subjected to parenteral administration of the additive, as he might be with a pharmaceutical product. Despite this, the early recommendations for carcinogenicity testing in the UK included subcutaneous injection tests in rodents. There is no doubt that the subcutaneous test has proved a quick and convenient tool for research in cancer, and appears to be acceptable to most experts for this purpose. However, the methods used to study the basic mechanism of carcinogenic activity are not necessarily the best for studying the practical assessment of possible cancer hazard from food additives in the human diet. If the purpose is only to study cancer, then it does not matter how this cancer is produced as every new method may throw some light on causation. For food additives, however, it should be kept clearly in mind that demonstrations of carcinogenic activity are not at all valid if they can be due to the method of administration. The special nature of cancer, with the strong emotional response to any suggestion that a chemical in use could cause cancer, should be borne in mind when tests involving indirect administration are being considered. Objective assessment of an effect labelled as cancer can be extremely difficult and for politicians almost impossible. Even when the oral route is adopted, there may be doubt as to the part played by the chemical in stimulating or initiating cancer, but by the subcutaneous route it is almost impossible to identify the most significant causative factor.

At the time when the Polyster WOL programme began, the subcutaneous injection of the test substance was considered to be an acceptable example of a stringent test and many scientists accepted this without question. However, despite the fact that benign or malignant cancer can certainly be produced in this way when a variety of chemicals are injected, there was a growing belief that this was not a suitable test (Roe, 1966; Food Protection Committee and Others, 1967; Shubik, Saffiotti, Lijinsky, Pietra, Rappaport, Toth, Rahn, Tomatis \& Feldman, 1962). This subject has been dealt with at greater length by Philp (1968). Fortunately, over the years, reasoned argument and experimental work (Grasso \& Golberg, i966) has led to a change in the UK acceptance of the obligatory nature of subcutaneous 
tests. Good evidence that an additive is absorbed in the test animal allows the feeding trial to be the only essential test for carcinogenicity.

Critical appraisal of test methods and of interpretation will continue and it now seems opportune to focus attention on the significance of liver cancer produced in laboratory animals by repeated administration of doses toxic to the liver tissue. If results are achieved in animals only after the use of high dosage, long exposure and with prolonged tissue damage prior to establishment of carcinogenic change, it is highly unlikely that this could be relevant to the use by humans of 'additive' levels of the chemical. Safrole was banned on suspicion of being a carcinogen after just such a test. This chemical is a constituent of essential oils, for example Sassafras albidum L. Until being labelled as a carcinogen, it was used in small amounts to flavour soft drinks in the USA. The investigators used high levels continuously administered in the diet and obtained liver tumours after extensive pathology in the liver (Long, Nelson, Fitzhugh \& Hansen, I963). It would seem more rational to discuss the hepatotoxicity of the chemical and, if no-effect levels could be demonstrated, allow its use at levels of intake which provide the usual margins of safety. To do otherwise allows no distinction between safrole and a carcinogen such as aflatoxin which when given in doses amounting to only a few parts $/ 10^{6}$ of the diet can produce its effect within the first months of testing and direct on liver cells with no chronic damage intervening (Lancaster, Jenkins \& Philp, I96r).

Other chemicals such as chloroform, unrelated to the food additive scene, have also been labelled carcinogens after similar tests (Eschenbrenner, 1944) and the liver reaction seems worthy of study irrespective of its relevance to food additives.

Greater knowledge of metabolic activity in the liver cannot help but be of great value to all aspects of food additive testing. The greatest problem in the future may well be the difficulty in bringing together all the relevant factors from diverse disciplines and techniques to allow proper interpretation of observed phenomena. Once again, therefore, one has to emphasize the need for multidisciplinary cooperative effort in the ever widening field of food additive testing.

\section{REFERENCES}

Barnes, J. M. (1960). Fd Drug Cosmet. Law March, p. 162.

Barnes, J. M. \& Denz, F. A. (1954). Pharmac. Rev. 6, 191.

Collings, A. J. \& Favell, D. (r97r). The Metabolism of Sodium Cyclamate. (In the Press.)

Epstein, S. S. \& Röhrborn, G. (1971). Nature, Lond. 230, 459.

Epstein, S. S. \& Shafner, H. (I 968). Nature, Lond. 219, 385.

Eschenbrenner, A. B. (1944). F. natn. Cancer Inst. 5, $25 \mathrm{I}$.

Food Protection Committee and Others (1967). Use of Human Subjects in Safety Evaluation of Food Chemicals. Washington D.C. : National Academy of Sciences, National Research Council.

Frazer, A. C. (1964). F. Soc. cosmet. Chem. November, p. I7.

Freund, P. A, (1965). New Engl. F. Med, 273, 687 .

Grasso, P. \& Golberg, L. (1966). Fd Cosmet. Toxicol. 4, 297.

Hayes, W. J. (1968). In Modern Trends in Toxicology p. I98 [E. Boyland and R. Goulding, editors]. London: Butterworths.

Kosima, S. \& Ichibagase, H. (1966). Chem. pharm. Bull., Tokyo r4, $97 x$.

Lancaster, M. C., Jenkins, F. P. \& Philp, J. McL. (196r). Nature, Lond, r92, 1095.

Leahy, J. S., Wakefield, M. \& Taylor, T. (I967). Fd Cosmet. Toxicol. 5, 447.

Lehman, A. J., Laug, E. P., Woodward, G., Draize, J. H., Fitzhugh, O. G. \& Nelson, A. A. (I949). Fd Drug Cosmet. Law Quart. 4, 412. 
Vol. $3^{\text {I }}$

Long, I. E., Nelson, A. R., Fitzhugh, O. G. \& Hansen, W. H. (Ig63). Archs Path. 75, 595.

Philp, J. McL. (I968). In Modern Trends in Toxicology ch. I2 [E. Boyland and R. Goulding, editors]. London: Butterworths.

Roe, F. J. C. (1966). Sci. F. 2, $3^{8}$.

Shubik, P., Saffiotti, V., Lijinsky, W., Pietra, G., Rappaport, H., Toth, B., Rahn, C. R., Tomatis, L. \& Feldman, R. (1962). Toxicol. appl. Pharmac. Suppl. no. 4.

Wilson, R., Doell, B. H., Groger, W., Hope, J. \& Gellatly, J. B. M. (1970). In Metabolic Aspects of Food Safety p. 363. Oxford: Blackwell Scientific Publications. 